Pak. j. sci. ind. res. Ser. A: phys. sci. 2021 64A(2) 97-102

\title{
Effect of Mechanical Properties in Enhanced Polymeric Blend Membranes
}

\author{
Asim Mushtaq*ab, Hilmi Bin Mukhtar ${ }^{\mathrm{b}}$ and Azmi Mohd Shariff ${ }^{\mathrm{b}}$ \\ aPolymer and Petrochemical Engineering Department, NED University of Engineering \& Technology, \\ Karachi, Sindh, Pakistan \\ ${ }^{\mathrm{b}}$ Chemical Engineering Department, Universiti Teknologi PETRONAS, 32610 Bandar Seri Iskandar, \\ Perak Darul Ridzuan, Malaysia
}

(received November 12, 2019; revised July 17, 2020; accepted July 23, 2020)

\begin{abstract}
This study was carried out to evaluate the effect of blending the rubbery and glassy polymer with an alkanolamine on the mechanical properties. Due to the intrinsic properties of glassy polysulfone (PSU) and rubbery polyvinyl acetate (PVAc), optimizing their properties by blending both polymers is expected to address the shortage. The enhanced polymeric blend membrane (EPBM) was developed by varying the composition of PVAc ranging from 5 to $20 \mathrm{wt}$. $\%$ with 95 to $80 \mathrm{wt}$. $\%$ base PSU in dimethylacetamide (DMAc) solvent. The DEA amine composition was added to the blend and kept at $10 \mathrm{wt} \%$ over solvent. The tensile analysis technique is utilized to evaluate the mechanical behaviour of a polymeric material which comprises the deformation of the polymeric material underneath the effect of an applied force prior to failure. The mechanical analysis showed improvement in tensile strength, Young's modulus and elongation at break properties with the increase in PVAc/DEA composition in the enhanced polymeric blend membranes. The elongation at break property increased with an increase in the amine contents which indicated the flexibility of the EPBM. In addition, the mechanical analysis revealed remarkable enhancement in the mechanical properties of the EPBM which might be attributed to the robust interactions among the PSU blend with PVAc and DEA.
\end{abstract}

Keywords: diethanolamine, enhanced polymeric blend membrane, polysulfone, polyvinyl acetate, tensile strength

\section{Introduction}

Absorption, adsorption and cryogenic technologies are available for low concentration of $\mathrm{CO}_{2}$ in feed, but their installations for offshore applications are a major concern due to the huge floor area requirement as well as high energy consumption (Mahdi and Tan, 2016; WolinskaGrabczyk and Jankowski, 2015). Currently, polymer membranes and inorganic membranes were considered for gas separation. However, there are some limitations of polymer membranes such as high permeability and selectivity (Marjan, 2016; Kim and Lee, 2015).

In order to optimize the benefits of both polymers, the blending of glassy with rubbery polymers improve membrane properties for gas separation. In addition to the polymeric blend membrane that has many advantages regarding permeability, selectivity, thermal, mechanical and chemical stability. Polymeric blending material also compromises a time-cost effective method to develop new materials with desired properties. To enhance the

*Author for correspondence;

E-mail: engrasimmushtaq@yahoo.com compatibility of the polymer blend, a third component such as alkanolamine is added. It is expected that the addition of alkanolamine will improve PBM properties. Amine solutions help to purify acidic natural gas. Hence, a practical approach to membrane enhancement includes blending amines (MEA, DEA and MDEA) with polymers to develop Enhanced Polymeric Blend Membranes (EPBM). Amine addition to the polymer blend may affect the polymer's capacity for absorption, and thus, allow enhanced the properties of the membrane (George et al., 2016; Mansourpanah and Gheshlaghi 2012).

The objective of this study is to analyze the mechanical stability of the Enhanced polymeric blend membrane. The tensile investigation is utilized to break down the material's mechanical behaviour which includes the deformation of the polymeric material affected by an applied force prior to failure (Mukhtar et al., 2016; Sgreccia et al., 2010). The tensile test is the reaction of the applied force that is noted in a stress-strain curve, appraises the quality of the polymeric material and its determination for a specific application (Vladimirov 
et al., 2006). It is one of the best ways to evaluate mechanical properties and has been extensively used owing to its simple, robust and inexpensive parameters. DMA technique was used to study the viscoelastic properties of a material. Dynamic mechanical analysis can be defined as applying an oscillatory force (stress, $\gamma$ ) to an illustration and evaluating the material's response (strain, $\sigma$ ) to that force. The stress is applied sinusoidaly with a defined frequency, which causes a sinusoidal strain (Venna et al., 2015; Stamm, 2006).

\section{Materials and Methods}

The composition of developed membranes tested for tensile strength is given in Table 1. The tensile strength, Young's modulus and interrelated properties of the synthesized polymeric blend membranes were evaluated by using the ASTM D882-02 method for membrane thickness less than $1.0 \mathrm{~mm}$ at $\sim 24^{\circ} \mathrm{C}$. Figure 1 shown the dumb-bell sample specimen, had dimensions of 100 $\mathrm{mm} \times 9 \mathrm{~mm}$. It was established for 10 replications using the Fowler ${ }^{\circledR}$ digital micrometer (Basu et al., 2010).

Table 1. List of membranes developed in this study

\begin{tabular}{llll}
\hline \hline & \multicolumn{2}{c}{ Polymer } & \\
\cline { 2 - 3 } $\begin{array}{l}\text { Membrane } \\
\text { code }\end{array}$ & $\begin{array}{l}\text { PSU } \\
\text { (wt. \%) }\end{array}$ & $\begin{array}{l}\text { PVAc } \\
\text { (wt. \%) }\end{array}$ & $\begin{array}{l}\text { Amine10 } \\
\text { wt. \% }\end{array}$ \\
\hline M1 & $100 \%$ & 0 & - \\
M2 & 0 & $100 \%$ & \\
M3 & $95 \%$ & $5 \%$ & \\
M4 & $90 \%$ & $10 \%$ & \\
M5 & $85 \%$ & $15 \%$ & \\
M6 & $80 \%$ & $20 \%$ & \\
M7 & $100 \%$ & - & DEA \\
M8 & $95 \%$ & $5 \%$ & DEA \\
M9 & $90 \%$ & $10 \%$ & \\
M10 & $85 \%$ & $15 \%$ & \\
M11 & $80 \%$ & $20 \%$ & \\
\hline \hline
\end{tabular}

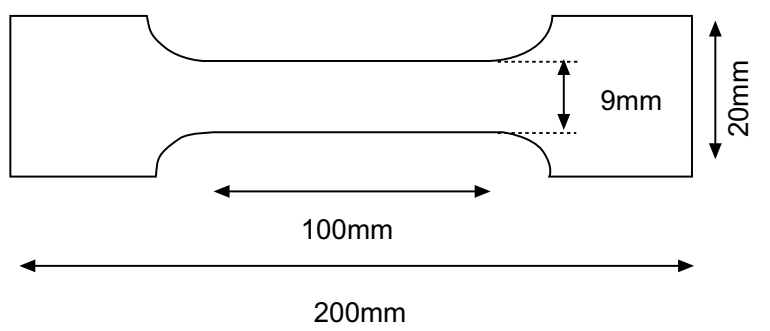

Fig. 1. The dumbbell-shaped specimen for tensile testing.
Then, it was tested on LR 5K Lloyd universal testing machine at a constant grip separation rate. The test speed $12.50 \mathrm{~mm} / \mathrm{min}$ and span $30.0 \mathrm{~mm}$.

For each membrane sample, this test was repetitive to obtain the average tensile properties. The membrane sample was positioned among the two grips then gripped with the first one is fixed to a stationary crosshead chamber and another with a movable chamber. This assembling not permitted the sample from slippage and irregular stress detachment. The change in length (L$\mathrm{L}_{\mathrm{o}}$ ) of the specimen regarding the original length $\left(\mathrm{L}_{\mathrm{o}}\right)$ was noted once the force or load (P) was applied to pull the membrane sample in the opposed direction with the original cross-section area $\left(\mathrm{A}_{\mathrm{o}}\right)$ (Linares and Acosta, 2004; Cui et al., 1998). The information obtained from these load measurements and elongation were used to analyze the stress (s) and strain (e) that were resolved utilizing the accompanying equations:

$\varepsilon=\frac{\left(\mathrm{L}-\mathrm{L}_{\mathrm{o}}\right)}{\mathrm{L}_{\mathrm{o}}}$

$\sigma=\frac{p}{A_{o}}$

$\%$ strain at break $=100$

Young's modulus is determined by the tensile strength curve. Young's modulus is the stiffness of material signifies the stress created in the limit of the small deformation formed in the material (Stamm, 2006; Musto et al., 2004).

\section{Results and Discussion}

Mechanical properties of polymeric blend membranes. The properties of the symmetric polymeric blend membrane films were evaluated based on the mechanical analysis. The representative tensile strength curves of the developed base PVAc membrane and base PSU membrane with different composition of PVAc blend is shown in Fig. 2-3 respectively.

Tensile strength, Young's modulus, elongation, stress and strain at break are summarised in Table 2. The different samples showed different behaviour in their properties at varying percentages of the polymers used. The tensile strength curve indicates that after the initial stroke intervals, the membrane samples started to deviate 
from the linear relationship and reached a new equilibrium state after undergoing an intermolecular rearrangement in their structure, it may be due to the presence of PVAc in PSU membranes (Prasad et al., 2008).

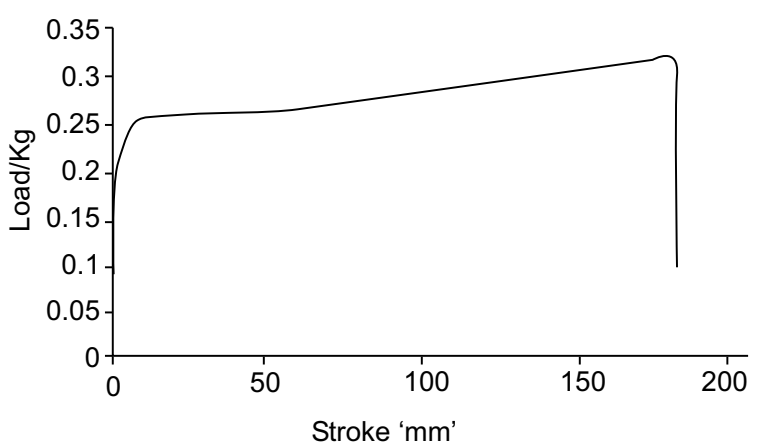

- Pure PVAc membrane

Fig. 2. Tensile strength curve of base PVAc membrane.

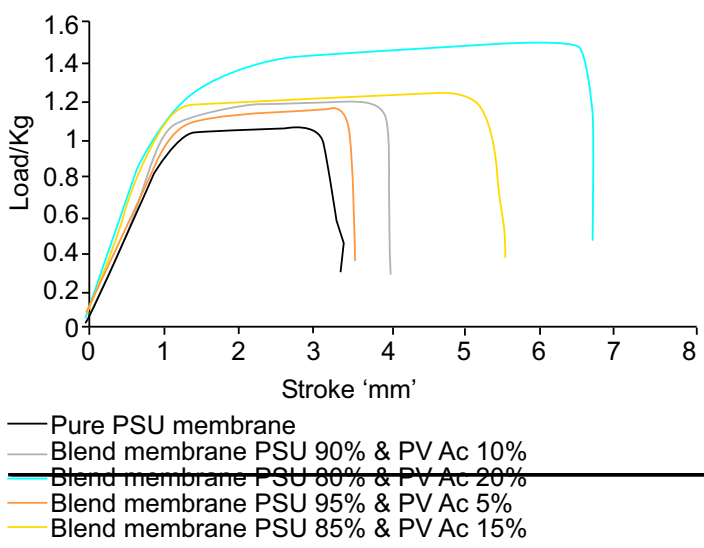

Fig. 3. Tensile strength curve of polymeric blend membranes.
It is observed that the strain and elongation gradually increased with the addition of PVAc composition in the PSU membranes. In comparison to the base PSU membrane, PSU/PVAc (80/20) wt. \% showed higher brittle characteristics and fractures at $3.994 \%$ strain, so the maximum elongation was $26.762 \%$ and 127.893 $\mathrm{N} / \mathrm{mm}^{2}$ Young's modulus. It is because PSU possesses a polar $\mathrm{SO}_{2}$ group and rigid aromatic rings in its backbone structure with intrinsic values of tensile strength and Young's modulus (Chen and Iroh, 1999). On the other hand, PVAc exceeded the intrinsic tensile properties of PSU, indicating the decreased rigidity of the membrane blends due to the vinyl acetate group (Stamm, 2006). The results, thus, obtained by the symmetric polymeric blend membranes shows similar behavior as reported by Linares and Acosta on a membrane system (Linares and Acosta 2004). Their results showed improved brittle characteristics and fractures to break at $5.107 \mathrm{~N} / \mathrm{mm}^{2}$ as the maximum tensile strength and Young's modulus of $127.893 \mathrm{~N} / \mathrm{mm}^{2}$ as compared to base PVAc membrane.

The plot of tensile strength, Young's modulus and elongation as a function of the PVAc contents are shown in Fig. 4. The decreasing trend of tensile strength and Young's modulus was observed with the increased PVAc content in PSU that indicates a weak interfacial interaction between the membrane blends. A minimum value of tensile strength and Young's modulus were observed with the addition at $20 \mathrm{wt}$ \% PVAc, as compared to the pure PSU membrane. While the elongation increased almost linearly with the increase in the PVAc contents and increased up to $26.762 \%$ at 20 wt. \% PVAc. This linear increase reflected a more elastic characteristic of the membrane blend with respect to the base PSU membrane and indicated a stronger chain entanglement in the films thus leading to a longer

Table 2. Mechanical properties of the developed PSU/PVAc blend membranes

\begin{tabular}{llllllll}
\hline \hline $\begin{array}{l}\text { Membrane } \\
\text { coding }\end{array}$ & $\begin{array}{l}\text { Tensile } \\
\text { strength } \\
\mathrm{N} / \mathrm{mm}^{2}\end{array}$ & $\begin{array}{l}\text { Young } \\
\text { modulus } \\
\mathrm{N} / \mathrm{mm}^{2}\end{array}$ & $\begin{array}{l}\text { Stress } \\
\mathrm{N} / \mathrm{mm}^{2}\end{array}$ & $\begin{array}{l}\text { Strain } \\
\%\end{array}$ & $\begin{array}{l}\text { Yield } \\
\text { strength } \\
\mathrm{N} / \mathrm{mm}^{2}\end{array}$ & $\begin{array}{l}\text { Elongation } \\
\mathrm{mm}\end{array}$ & $\begin{array}{l}\text { Elongation } \\
\%\end{array}$ \\
\hline M1 & 7.351 & 244.155 & 7.328 & 3.001 & 6.808 & 3.371 & 13.483 \\
M2 & 0.601 & 23.739 & 1.007 & 4.245 & 0.679 & 178.491 & 713.964 \\
M3 & 6.136 & 206.511 & 6.378 & 3.088 & 5.314 & 3.566 & 14.224 \\
M4 & 5.891 & 194.043 & 6.091 & 3.139 & 5.205 & 4.010 & 16.040 \\
M5 & 5.513 & 160.85 & 5.482 & 3.408 & 5.174 & 5.504 & 22.017 \\
M6 & 5.107 & 127.893 & 5.106 & 3.994 & 5.095 & 6.690 & 26.762 \\
\hline \hline
\end{tabular}




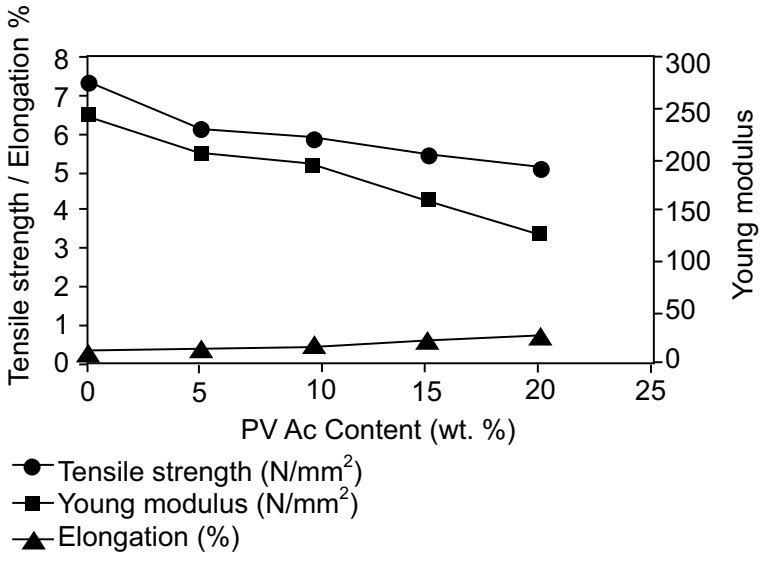

Fig. 4. Young's modulus, tensile strength and elongation at the break for membrane blends as a function of the PVAc content in PSU.

elongation. The tensile strength and Young's modulus of the polymeric blend membranes showed a decreasing trend. The strength is generally degraded due to aggregation (Venna and Carreon, 2010; Menard, 1999). Thus, the results obtained by the symmetric membranes show similar trends for Young's modulus and tensile strength as reported by Ma. Josephine C. Ordonez et al. (2010) on a Matrimid $\AA / Z I F-8$ mixed matrix membranes (Ordoñez et al., 2010).

Mechanical properties of enhanced polymeric blend membranes (EPBM). The effect of PVAc and DEA addition in pure PSU membrane, the mechanical properties of membranes were determined by tensile testing from the universal testing machine (UTM). Figure 5 shows the Tensile strength curve of PSU/DEA membrane (M-7) and PSU/PVAc/DEA (M-8 to M-11). Tensile strength, Young's modulus, stress, strain and elongation at break summarized in Table 3.

The tensile strength curves (Fig. 5) show the linear relation between load and stroke for all membranes.



Fig. 5. Tensile strength curve of enhanced polymeric blend membranes.

The tensile strength curve also indicated that by the addition of DEA and different composition of PVAc the samples started to deviate from the linear relationship and reached a new equilibrium state after undergoing an intermolecular rearrangement in their structure, it might be due to the presence of DEA and PVAc in PSU matrix (Mansourpanah and Gheshlaghi, 2012). It also noticed that the concentration of DEA $(10 \mathrm{wt} . \%)$ in PSU/PVAc membranes showed increased strain and stress. This might be due to less degree of crystallinity of membranes by the addition of DEA. The tensile strength curve of all membranes shown yield point, and in the experimental conditions used, it is observed the breakpoint and also the elongation at break, so synthesized membranes present a reasonably tenacity and toughness.

It is observed in Table 3 and Fig. 6 that Young's modulus gradually increased with the addition of PVAc and DEA in PSU. The M-11 membrane showed the highest value of Young's modulus $\left(103.818 \mathrm{~N} / \mathrm{mm}^{2}\right)$. The tensile

Table 3. Mechanical properties of the developed PSU/PVAc/DEA blend membranes

\begin{tabular}{llllllll}
\hline \hline $\begin{array}{l}\text { Membrane } \\
\text { coding }\end{array}$ & $\begin{array}{l}\text { Tensile } \\
\text { strength } \\
\mathrm{N} / \mathrm{mm}^{2}\end{array}$ & $\begin{array}{l}\text { Young } \\
\text { modulus } \\
\mathrm{N} / \mathrm{mm}^{2}\end{array}$ & $\begin{array}{l}\text { Stress } \\
\mathrm{N} / \mathrm{mm}^{2}\end{array}$ & $\begin{array}{l}\text { Strain } \\
\%\end{array}$ & $\begin{array}{l}\text { Yield } \\
\text { strength } \\
\mathrm{N} / \mathrm{mm}^{2}\end{array}$ & $\begin{array}{l}\text { Elongation } \\
\mathrm{mm}\end{array}$ & $\begin{array}{l}\text { Elongation } \\
\%\end{array}$ \\
\hline M7 & 1.633 & 82.616 & 3.046 & 3.687 & 1.531 & 4.096 & 16.383 \\
M8 & 1.896 & 86.146 & 2.251 & 2.613 & 1.697 & 4.714 & 18.856 \\
M9 & 2.305 & 97.743 & 2.901 & 2.968 & 2.209 & 6.170 & 24.679 \\
M10 & 2.717 & 101.696 & 3.238 & 3.184 & 2.655 & 9.508 & 38.031 \\
M11 & 2.918 & 103.818 & 3.725 & 3.588 & 2.835 & 10.313 & 41.251 \\
\hline \hline
\end{tabular}




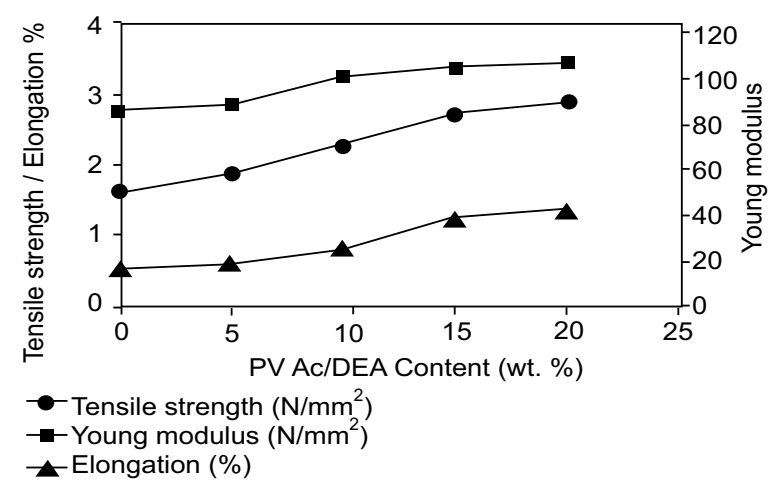

Fig. 6. Young's modulus, tensile strength and elongation at the break for membrane blends as a function of the PVAc/DEA content in PSU.

strength is also increased with the addition of PVAc and DEA in PSU.

In comparison to the base PSU membrane, the strain at break values of M-7 and M-11 is higher. The increasing trend of Young's modulus shows good interfacial contact between PSU and PVAc/DEA. It is also confirmed that the addition of DEA amine was enhanced the blending compatibility with both phases. The enhanced polymeric blend membranes also exhibit the synergetic effect of PVAc and DEA on Young's modulus. The increase in Young's modulus is also due to the increase of polymer chain entanglement with PVAc and DEA contents which leads to constraining the polymer chain mobility resulting in a stiffer film. It is a further strength by the presence of polar $-\mathrm{SO}^{-2}$, DEA group and rigid aromatic ring in PSU backbone, hence the value of Young's modulus of membranes showed an increasing trend at low concentration of PVAc and DEA. The tensile strength of the EPBM showed an increasing trend. The strength is generally enhanced due to aggregation (Basu et al., 2010; Sgreccia et al., 2010; Vladimirov et al., 2006). Thus, the results obtained by the symmetric membranes show similar trends for Young's modulus and tensile strength as reported in the literature (Mohshim et al., 2018; Ordoñez et al., 2010).

\section{Conclusion}

In addition, the mechanical analysis revealed remarkable improvements in the mechanical properties of the enhanced polymeric blend membranes which may be attributed to the strong interactions between the PSU, PVAc and DEA. Mechanical analysis indicated a steady increase in Young's modulus and tensile strength up to 10 wt. \% DEA loading. The kinetic analysis and mechanical properties performed on the developed membranes showed that the activation energies and tensile properties both increased with the increase in the PVAc/DEA contents in PSU and PSU/PVAc/DEA (80/20) wt. \% showed maximum improvement.

\section{Acknowledgment}

The authors would like to acknowledge the Universiti Teknologi PETRONAS for supporting this research work and the NED University of Engineering and Technology, Karachi, Pakistan for financial support to Asim Mushtaq studying at this University.

\section{Nomenclature}

DEA=Diethanolamine; PSU=Polysulfone; $\mathrm{EPBM}=$ Enhanced Polymeric Blend Membranes; PVAc= Polyvinyl Acetate; $\mathrm{PBM}=$ Polymeric Blend Membranes

Conflict of Interest. The authors declare no conflict of interest.

\section{References}

Basu, S., Cano-Odena, A., Vankelecom, I.F.J. 2010. Asymmetric Matrimid $\AA /\left[\mathrm{Cu}_{3}(\mathrm{BTC})_{2}\right]$ mixedmatrix membranes for gas separations. Journal of Membrane Science, 362: 478-487.

Chen, Y., Iroh, J. O. 1999. Synthesis and characterization of polyimide/silica hybrid composites. Chemistry of Materials, 11: 1218-1222.

Cui, W., Kerres, J., Eigenberger, G. 1998. Development and characterization of ion-exchange polymer blend membranes. Separation and Purification Technology, 14: 145-154.

George, G., Bhoria, N., AlHallaq, S., Abdala, A., Mittal, V. 2016. Polymer membranes for acid gas removal from natural gas. Separation and Purification Technology, 158: 333-356.

Kim, S., Lee, Y. M. 2015. Rigid and microporous polymers for gas separation membranes. Progress in Polymer Science, 43: 1-32.

Linares, A., Acosta, J. L. 2004. Structural characterization of polymer blends based on polysulfones. Journal of Applied Polymer Science, 92: 3030-3039.

Mahdi, E. M., Tan, J.-C. 2016. Mixed-matrix membranes of zeolitic imidazolate framework (ZIF-8)/Matrimid nanocomposite: Thermo-mechanical stability and 
viscoelasticity under pinning membrane separation performance. Journal of Membrane Science, 498: 276-290.

Mansourpanah, Y., Gheshlaghi, A. 2012. Effects of adding different ethanol amines during membrane preparation on the performance and morphology of nanoporous PES membranes. Journal of Polymer Research, 19: 3-7.

Marjan, F. H.M., Azmi, M.S. 2016. An investigation of blended polymeric membranes and their gas separation performance. The Royal Society of Chemistry, 6: 102671-102679.

Menard, K.P. 1999. Dynamic Mechanical Analysis: A Practical Introduction (Vol. 1). CRC Press. New York, USA.

Mohshim, D.F., Mukhtar, H., Man, Z. 2018. A study on carbon dioxide removal by blending the ionic liquid in membrane synthesis. Separation and Purification Technology, 196: 20-26.

Mukhtar, H., Mannan, H.A., Minh, D., Nasir, R., Moshshim, D. F., Murugesan, T. 2016. Polymer blend membranes for $\mathrm{CO}_{2}$ separation from natural gas. Paper presented at the International Conference on Chemical Engineering and Bioprocess Engineering, Sabah, Malaysia.

Musto, P., Ragosta, G., Scarinzi, G., Mascia, L. 2004. Polyimide-silica nanocomposites: spectroscopic, morphological and mechanical investigations. Polymer, 45: 1697-1706.

Ordoñez, M.J.C., Balkus, K.J., Ferraris, J.P., Musselman, I.H. 2010. Molecular sieving realized with ZIF8/Matrimid® mixed-matrix membranes. Journal of Membrane Science, 361: 28-37.

Prasad, P., Guru, G.S., Shivakumar, H.R., Rai, K.S. 2008. Miscibility, thermal, and mechanical studies of hydroxypropyl methylcellulose/pullulan blends. Journal of Applied Polymer Science, 110: 444-452.

Sgreccia, E., Chailan, J.F., Khadhraoui, M., Di Vona, M.L., Knauth, P. 2010. Mechanical properties of proton-conducting sulfonated aromatic polymer membranes: Stress-strain tests and dynamical analysis. Journal of Power Sources, 195: 77707775 .

Stamm, M. 2006. Introduction to physical polymer science. Macromolecular Chemistry and Physics, 207: 787-787.

Venna, S.R., Carreon, M.A. 2010. Highly permeable zeolite imidazolate framework-8 membranes for $\mathrm{CO}_{2} / \mathrm{CH}_{4}$ Separation. Journal of the American Chemical Society, 132: 76-78.

Venna, S.R., Lartey, M., Tao, Li, C.A.S., Kumar, S., Rosi, N.L., Albenze, E. 2015. Fabrication of MMMs with improved gas separation properties using externally-functionalized MOF particles. Journal of Materials Chemistry A, 3: 5014-5022.

Vladimirov, V., Betchev, C., Vassiliou, A., Papageorgiou, G., Bikiaris, D. 2006. Dynamic mechanical and morphological studies of isotactic polypropylene/ fumed silica nanocomposites with enhanced gas barrier properties. Composites Science and Technology, 66: 2935-2944.

Wolinska-Grabczyk, A., Jankowski, A. 2015. High performance membrane materials for gas separation. Copernican Letters, 6: 11-16. 